\title{
A critical study of the effects of flame retardancy on different knit fabrics
}

\begin{abstract}
A novel flame retardant especially Pekoflam HFC was synthesized to improve the flame retardancy of fabric. Pekoflam HFC is especially suitable for flame retardant back coatings of synthetic fibre based home textiles and high-performance technical textiles. The flame retardancy of the samples was characterized by the spray method and the vertical burning test. The results indicated that the flame retardant had excellent flame retardancy and durability for cellulosic fabrics. The cotton knit fabric treated with Pekoflam HFC obtained the optimum flame retardancy with the decreased char length. Combustion behaviors of treated cotton fabric were tested by manual observation. After treatment, it found that the ignition time increased, and the values of total heat release, heat release rate and mass loss decreased. The strength and durability of treated fabric were studied by tear force test and washing durability test, respectively.
\end{abstract}

Keywords: pekoflam HFC, flame retardant, spray techniques, cotton fabrics, flammability, durability
Volume 7 Issue 3 - 2021

\author{
Sheikh Sha Alam \\ Department of Textile Engineering, Port City International \\ University, Bangladesh
}

Correspondence: Sheikh Sha Alam, Assistant Professor and Chairman, Department of Textile Engineering, Port City International University, Chattogram, Bangladesh, Emailsheikhsha9@gmail.com

Received: May 16,202I | Published: May 26, 2021

\section{Introduction}

Textile substrates, particularly natural textiles, are easily ignited and highly flammable, posing a serious threat to persons and their belongings. ${ }^{1}$ Cotton is widely utilized in the domestic and industrial fields due to its favorable features such as regeneration, biodegradation, softness, comfort, warmth, and hygroscopic qualities. It is one of the most significant ecological textiles. On the other hand, this fabric has a strong inflammability due to its low limiting oxygen index and combustion temperature, which severely limits its use..$^{2-6}$

Flame retardants are a class of chemicals that are added to combustible materials to prevent fires from starting or to slow the progress of a fire so that more time is available to escape.

The flame retardant effect can be fast to mild washing conditions in combination with suitable hydrophobic binders. Due to the high surface area and the very low water solubility, the addition of a dispersing agent can be necessary when preparing the coating paste. As a combination with certain polymer binders can result in some cases in a destabilization of the polymer dispersion, proper selection of the binder system and adaptation of the dispersant system can be required. ${ }^{8}$

Hundreds of different flame retardants are available. Chemical structure and characteristics are frequently used to categorize them. Flame retardants are classified according to their content of bromine, chlorine, phosphorus, nitrogen, metals, or boron. ${ }^{9}$

Pekoflam HFC is especially suitable for flame retardant back coatings of synthetic fibre based home textiles and high-performance technical textiles. As a powder without substantial affinity to the textile material, it requires a combination with compatible polymer dispersions. ${ }^{10-12}$ The flame retardant effect can be fast to mild washing conditions in combination with suitable hydrophobic binders. ${ }^{13,14}$ In this case, Pekoflam HFC performs well with synthetic fabrics and mixes. It has better binder compatibility and a lower impact on rheological behavior commonly observed by increased viscosity when compared to other phosphorus-based powder flame retardants.

The Oeko-Tex Standard 100 recognized Pekoflam HFC as the first flame-retardant powder for the textile sector. The capacity of Pekoflam
HFC to combine the effects and qualities of specified halogenated and non-halogenated technologies in a fire protection solution for diverse coating polymers ${ }^{15}$ is its key benefit. Pekoflam HFC thus provides a long-term sustainable option for synthetic textile applications, meeting the Oeko-Tex Standard 100 standards and reacting to the general trend toward more ecologically friendly materials and end-products with lower health hazards. ${ }^{16}$

Pekoflam HFC is suitable for use in selected solvent-based coating systems but also for water-based coatings if combined with appropriate dispersing/wetting agents. Due to its very high-temperature stability and very low yellowing, as well as its low hygroscopic nature it is especially suitable for use in interior and transportation textiles, as well as for industrial protective wear. ${ }^{17,18}$

It can be combined with suitable polymer dispersions, preferably acrylates and polyurethanes. Depending on the application system and solvent type combination is also possible with PVC plastisols or solvent-based polyurethanes. In principle, it recommends preliminary lab trials to check the stability for combinations with other products. ${ }^{19-21}$

Due to the high surface area and the very low water solubility, the addition of a dispersing agent can be necessary when preparing the coating paste. Adaptation of the dispersant system can be required to adjust the system to the desired process parameters. Care should be taken to ensure that the necessary curing temperature for the binder used is employed, in case that coating fast to washing is required..$^{22}$

This project work aims to improve the flame retardancy property of fabric and to minimize the health risk from any kinds of fire or flame by using Pekoflam HFC flame retardant finish. After using chemical finish on 3 types of fabric, the flame retardancy has been tested and char length has been determined.

\section{Materials and methods}

\section{Materials}

Fabrics: 100\% Cotton knit Fabric has been used throughout the experiment and which is received from Base Textiles Ltd. Fabric. In this experiment, 3 different fabric samples were used such as a single jersey, $1 \times 1$ Rib, and Terry. 


\section{Chemicals and reagents}

Pekoflam HFC is a phosphorus/nitrogen organic chemical that performs well on synthetic textiles, such as polyamide fibres and blends. When compared to frequently utilized nitrogen, the unique chemistry is more efficient. It can be used in both water-based and Oeko-Tex standard 100 compliant green solvent-based coating processes. Because of the ecological profile, it can be used for both indirect and direct skin contact. The capacity of Pekoflam HFC to combine the effect and qualities of selected halogenated and nonhalogenated technologies in a fire protection solution for various coating polymers is its key benefit. Pekoflam HFC thus offers a sustainable long term alternative for synthetic textiles application, meeting the Oeko-Tex standard 100 and responding to the general trend towards more environmentally compatible materials and products that pose a significantly lower health risk (Figure 1) (Table $1)$.

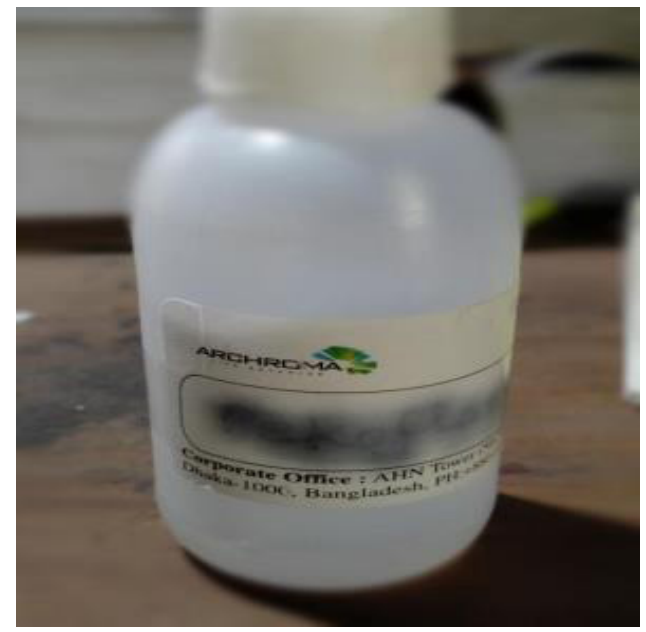

Figure I Pekoflam HFC.

Table I Properties of the Chemical

\begin{tabular}{ll}
\hline Appearance & White powder \\
\hline Chemical character & Organic phosphorus/nitrogen compound \\
lonic character & None \\
Solid content & About $100 \%$ \\
Density & About $1.4 \mathrm{~g} / \mathrm{cm} 3$ \\
pH & About 4- 6 \\
Phosphorus content & About 20-21 \% \\
Water content & $0.25 \%$ \\
Solubility & $\begin{array}{l}\text { Insoluble in water }(<\mathrm{g} / \mathrm{L}) \text { and common } \\
\text { organic solvents. }\end{array}$ \\
\hline
\end{tabular}

\section{Method of experiment}

Conventional scouring-bleaching: The sample fabrics (grey knit fabrics) were collected from Base Textiles Ltd., Bangladesh. Then the fabric was treated as single bath conventional scouring-bleaching. Sample dyeing machine of Base Textiles lab was used for the exhaust process. For this treatment $1.5 \mathrm{~g} / 1$ wetting agent, $1.5 \mathrm{~g} / 1$ sequestering agents, $4 \mathrm{~g} / 1$ caustic soda, $1.5 \mathrm{~g} / 1$ detergents, $1.5 \mathrm{~g} / 1$ stabilizers, $6 \mathrm{~g} / 1$ hydrogen peroxide, $\mathrm{M}: \mathrm{L}$ ratio was $1: 20$, and temperature $110^{\circ} \mathrm{C}$ for 45 minutes.
Sample preparation: After scouring and bleaching, the samples were prepared for the next process. The samples were cut at $8 \mathrm{~cm}$ widthwise and $30 \mathrm{~cm}$ lengthwise to perform the experimental work successfully.

Chemical treatment: In this experiment, the samples were developed at a one-step finishing process and that was the spray method or spray technique. Pekoflam HFC is first filled in a spray bottle and then a different structure of the cotton knit fabric is placed on the table serially one by one. After that, Pekoflam HFC flame retardant was sprayed in the fabric cutting specimen gradually. After completing the spray process, chemically treated specimens were dried in curing knit for 20 minutes. Then the vertical burning test was done to determine the thermal stability of the different knit structured fabric (Figure 2).

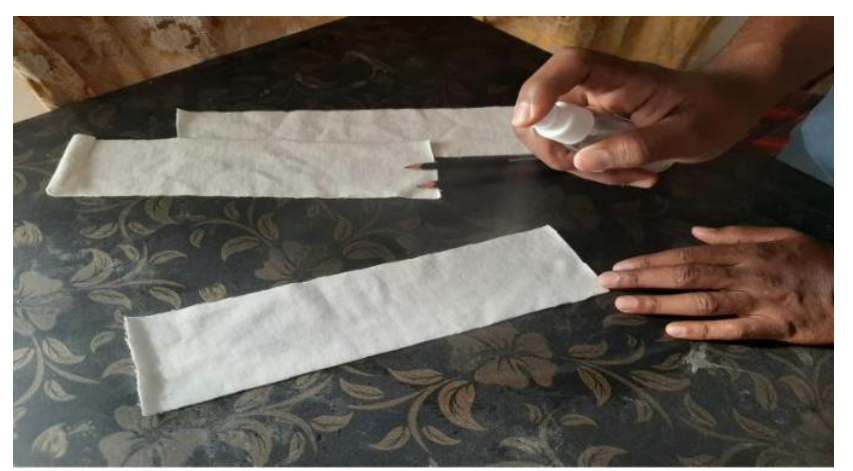

Figure 2 Pekoflam HFC spraying on fabric samples.

Method of testing vertical burning test: After drying, those specimens were undertaken for the vertical burning test. In this test process, firstly, the specimen was hanged through a burette stand. A gas burner was placed just below the fabric end. By considering a constant flame length which was $5 \mathrm{~cm}$ and a constant time for burning which was also $5 \mathrm{sec}$. Then started burning the sample which measurement was $30 \times 8 \mathrm{~cm}$. At first, the raw sample was burned which remained untreated. After that, the treated samples were burned. After burning the char length for both treated and untreated specimen were measured. And finally, noted the data for further analysis.

\section{Results and discussion}

\section{Flame retardant test}

In this experiment, the vertical flam test method (ASTM-6413) was used to determine the flammability test and analyses how LOI (Limiting Oxygen Index) effect flammability. LOI is defined as the minimum amount of oxygen in the oxygen/nitrogen mixture required to support combustion. Fibres having LOI value 21 or below ignite easily and burn rapidly in the open atmosphere. Sample with LOI above 21 ignites but slowly (Figure 3).

\section{Flame retardant test on single jersey structure}

Pekoflam HFC treated fabric shows flame retardant properties on different structured woven fabric (as shown in (Table 2). During this experiment burning time and char length is calculated. Ignition time is the total time of burning time of a specimen. Char length is the total damage length of the fabric (Figure 4).

\section{Flame retardant test of $|x|$ rib structure}

Table 3 shows the data of char length. It shows that treated fabric is burned more than $1 \mathrm{x} 1 \mathrm{rib}$ untreated fabric. It exclaimed that after applying Pekoflam HFC fire retardance property increase then untreated fabric (Figure 5). 

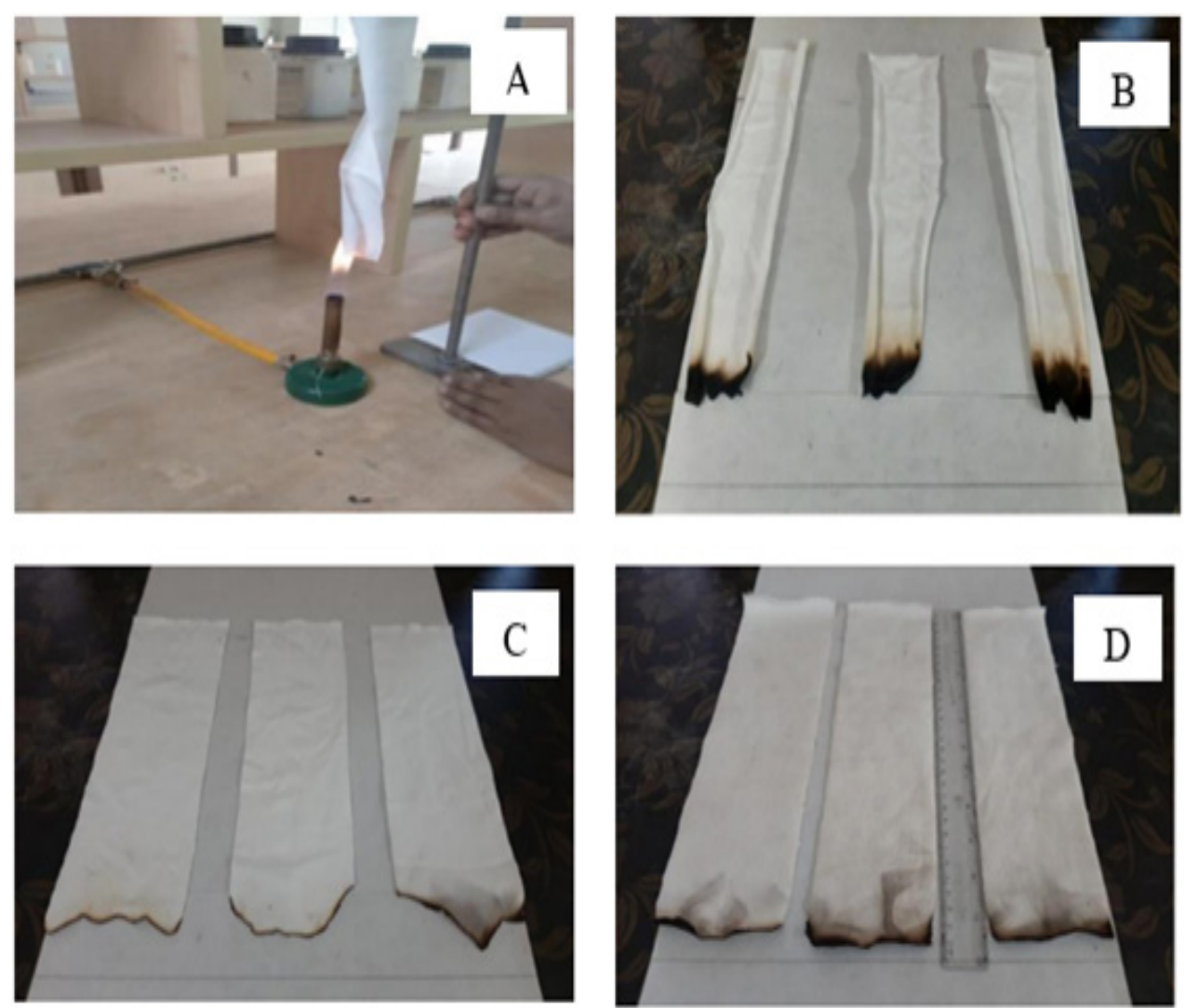

Figure 3 Flame retardant test (a.Vertical burning test; b. Burned sample for single jersey; c. Burned sample for I*I Rib; and d. Burned sample for terry fabric).
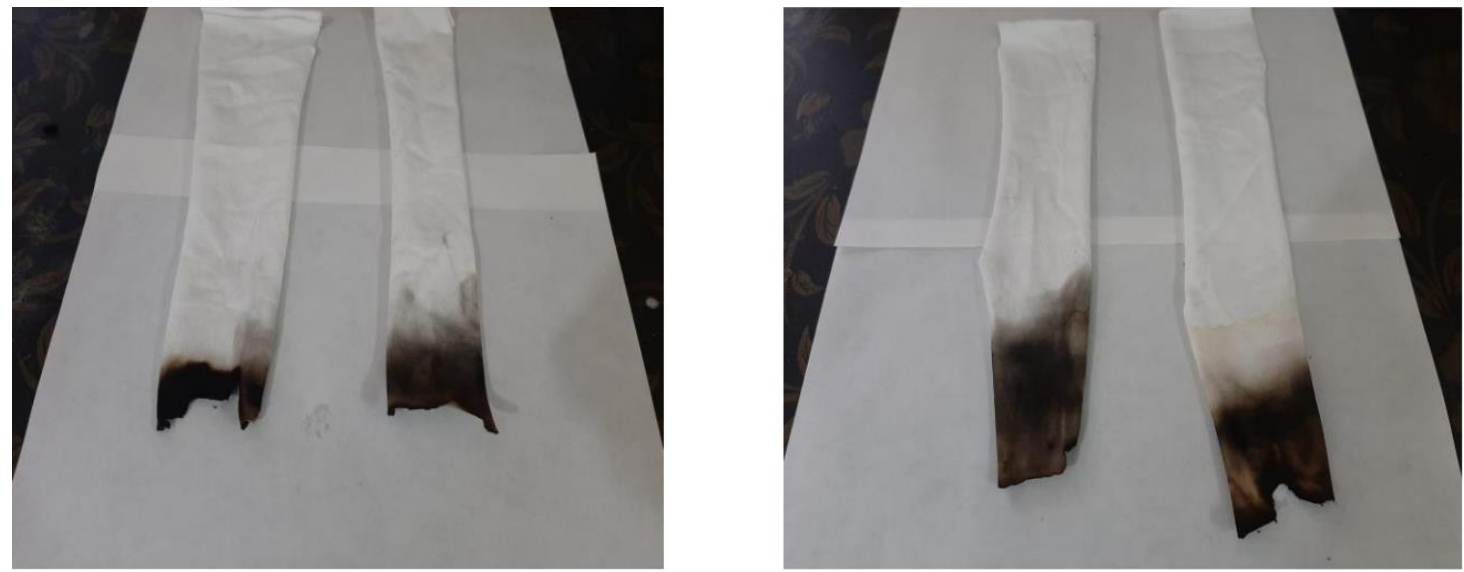

Figure 4 Pekoflam HFC effect of after treated (on the left) and untreated (on the right) samples on single jersey fabric.
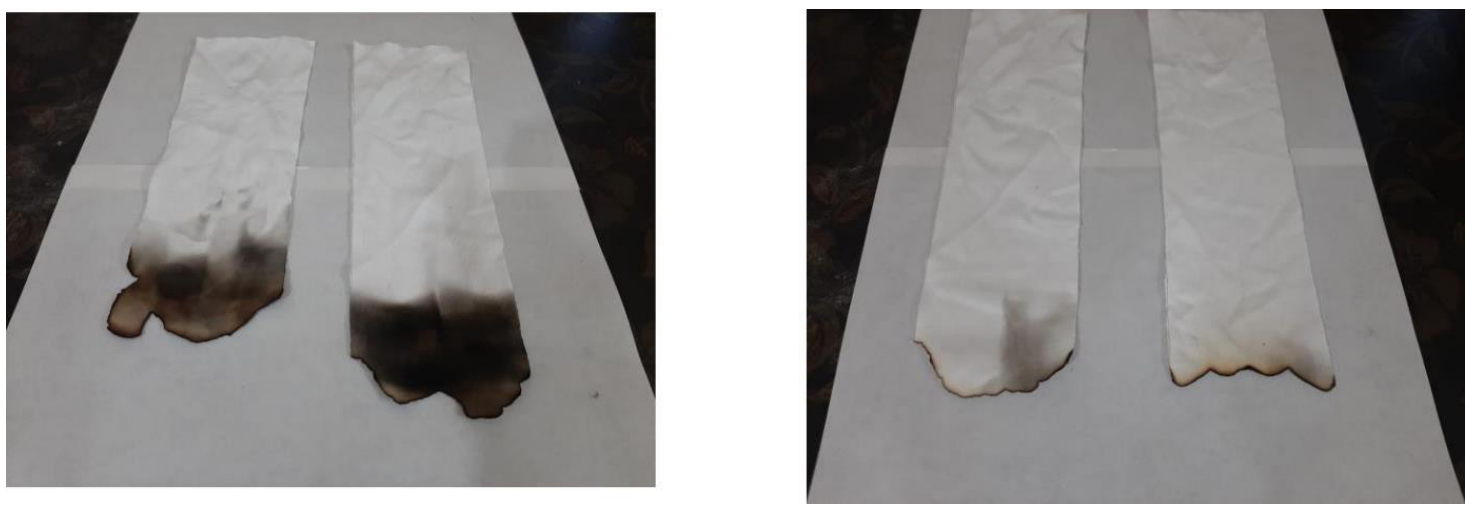

Figure 5 Pekoflam HFC effect of after treated (on the left) and untreated (on the right) samples on IxI rib fabric.

Citation: Alam SS.A critical study of the effects of flame retardancy on different knit fabrics.J Textile Eng Fashion Technol. 2021;7(3):105-109. DOI: 10.15406/jteft.202I.07.00275 
Table 2 Flame retardant test of single jersey fabric

\begin{tabular}{lllll}
\hline & $\begin{array}{l}\text { Flame } \\
\text { height }\end{array}$ & $\begin{array}{l}\text { Ignition } \\
\text { time }\end{array}$ & \multicolumn{2}{l}{ Char length $(\mathbf{c m})$} \\
\cline { 4 - 5 }$(\mathbf{c m})$ & $(\mathbf{s e c})$ & Untreated & Treated \\
\hline Sample 1 & 5 & 5 & 7 & 3.4 \\
Sample 2 & 5 & 5 & 6 & 3.1 \\
Sample 3 & 5 & 5 & 6 & 4.1 \\
Mean & & & & 3.53 \\
\hline
\end{tabular}

Table 3 Flame retardant test of $|x|$ rib

\begin{tabular}{|c|c|c|c|c|}
\hline \multirow{2}{*}{ Observation } & \multirow{2}{*}{$\begin{array}{l}\text { Flame } \\
\text { height } \\
(\mathrm{cm})\end{array}$} & \multirow{2}{*}{$\begin{array}{l}\text { Duration } \\
\text { (sec) }\end{array}$} & \multicolumn{2}{|c|}{ Char length $(\mathrm{cm})$} \\
\hline & & & Untreated & Treated \\
\hline Sample I & 5 & 5 & 5 & 2.8 \\
\hline Sample 2 & 5 & 5 & 4.5 & 2.3 \\
\hline Sample 3 & 5 & 5 & 5.2 & 1.9 \\
\hline Mean & & & & 2.33 \\
\hline
\end{tabular}

\section{Flame retardant test of terry structure}

Finally, In Table 4 presented all data with char length with treated and untreated fabric. It shows that Pekoflam HFC increases LOI in the fabric surface. The untreated bleached fabric has a certain amount of LOI. So it burns rapidly. But treated fabric contains more LOI so it can resist rapid burn (Figure 6).

Table 4 Flame retardant test of terry fabric

\begin{tabular}{lllll}
\hline Observation & $\begin{array}{l}\text { Flame } \\
\text { height } \\
(\mathbf{c m})\end{array}$ & $\begin{array}{l}\text { Duration } \\
(\mathbf{s e c})\end{array}$ & \multicolumn{2}{c}{ Char length $\mathbf{( c m )}$} \\
\cline { 4 - 5 } Sample 1 & & 5 & 3 & 0.9 \\
Sample 2 & 5 & 5 & 3.2 & 1.3 \\
Sample 3 & 5 & 5 & 3 & 0.7 \\
Mean & & & & 0.97 \\
\end{tabular}
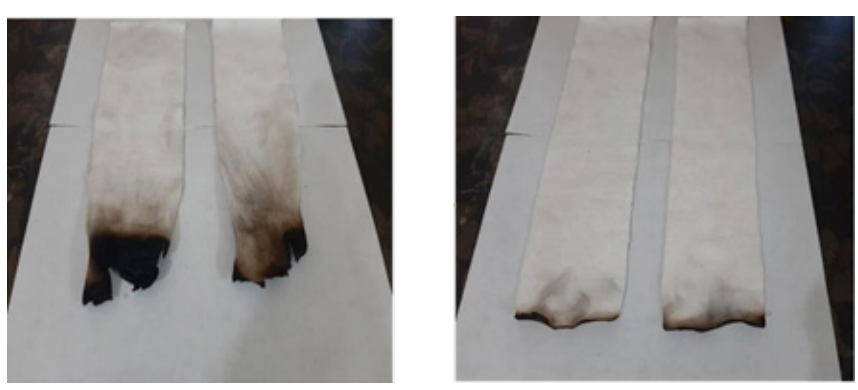

Figure 6 Pekoflam HFC effect of after treated (on the left) and untreated (on the right) samples on terry fabric.

From this figure, it shows that the treated status of Single Jersey, 1x1 Rib, and Terry Fabric (Figure 7). From this data, it concludes that single jersey caught fire rapidly than $1 \mathrm{x} 1$ rib and terry even on treated status. Because of its structure and nature, it catches fire rapidly and shows lower LOI. Single jersey shows very poor fire retardant than $1 \mathrm{x} 1 \mathrm{rib}$ and terry fabric. Pekoflam HFC has a nitrogen compound that can make a coating on fabric surface that can reduce LOI of fabric.

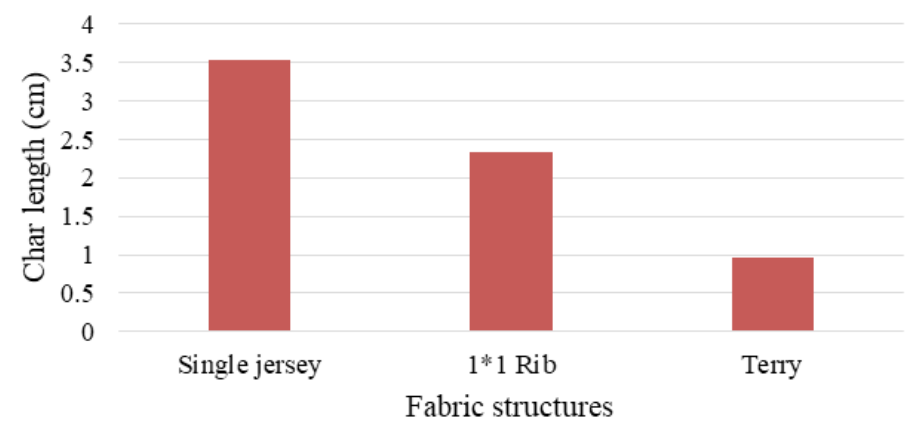

Figure 7 Char length vs fabric structure bar chart.

\section{Conclusion}

Pekoflam HFC is a halogen-free organic phosphorus or Nitrogen compound. Nitrogen compound can make a coating on the fabric surface and increase LOI value. Different structure of fabric shows different flame retardancy property after finishing the same flame retardant chemical. Fire retardant chemical can spray on fabric to improve its retardancy. The presence of Phosphorus/Nitrogen compound deposited on treated fabric can most positive parameter of char forming and decreases the flammability of fabric. More LOI value means more Flame retardant fabric. It is more environmentallycompatible materials and end-products that pose significantly lower risks to health. Finally, it found that Pekoflam HFC reduces fire hazard. In this project, it shows that with the increment of chemical's use on fabric in our daily life it will be beneficial to use this product as a flame retardant. To ensure the properties of flame retardant fabric, it has a great advantage to reduce fire accidents, this product can provide extra safety to our industry workers working inside the flame. Because it's quite easy to provide flame retardant fabric than to provide an extra safety suits and it is far comfortable then the suits.

\section{Acknowledgments}

The author would like to acknowledge M. Ahmed, Professor, Department of Textile Engineering, Port City International University, Chattogram, Bangladesh to provide proper guidelines to complete this project work successfully.

\section{Funding}

None.

\section{Conflicts of interest}

The authors report no declarations of interest.

\section{References}

1. Venkatraman P. Chapter 3 fabric properties and their characteristics.

2. Repon MR, Siddiquee NA, Jalil MA, et al. Flame retardancy enhancement of jute fabric using chemical treatment. Tekstilec. 2021;64(1), 70-80.

3. Uddin F. Introductory chapter: Textile manufacturing processes. 2019.

4. Toprak T, Anis P. Textile Industry's Environmental Effects and Approaching Cleaner Production and Sustainability: an Overview. Journal of textile engineering \& fashion technology. 2017;2(4).

5. Drumond Chequer FM, Rodrigues de Oliveira GA, Anastácio Ferraz ER, et al. Textile dyes: dyeing process and environmental impact. 2013.

6. Reinach. Archroma offers fire protection; repellency \& release, and coating solutions at techtextil India 2017. Why? Because it's Our Nature. 2017. 
7. Betts KS. New thinking on flame retardants. Environmental health perspectives. 2008;116(5):A210-A213.

8. Mandlekar N, Cayla A, Rault F, et al. An overview on the use of lignin and its derivatives in fire retardant polymer systems. 2018.

9. Aschberger K, Campia I, Pesudo LQ, et al. Chemical alternatives assessment of different flame retardants - A case study including multiwalled carbon nanotubes as synergist. Environment international. 2017;101:27-45.

10. Aldalbahi A, El-Naggar ME, El-Newehy MH, et al. Effects of technical textiles and synthetic nanofibers on environmental pollution. Polymers. 2021;13(1):155.

11. Muttenz. Clariant's new generation flame retardant: Pekoflam ${ }^{\circledR}$ ECO/ SYN.

12. Janice Wee. The truth about pants and women.

13. Papaspyrides CD, Pavlidou S, Vouyiouka SN. Development of advanced textile materials: Natural fibre composites, anti-microbial, and flameretardant fabrics. Proceedings of the Institution of Mechanical Engineers, Part L: Journal of Materials: Design and Applications. 2009;223(2):91102.

14. Samanta K, Basak S, Chattopadhyay S. Sustainable flame-retardant finishing of textiles: Advancement in technology. Handbook of Sustainable Apparel Production. 2015:51-76.
15. Coltelli MB, Wild F, Bugnicourt E, et al. State of the art in the development and properties of protein-based films and coatings and their applicability to cellulose based products: an extensive review. Coatings. 2015;6(1).

16. Lozhechnikova A, Bellanger H, Michen B, et al. Surfactant-free carnauba wax dispersion and its use for layer-by-layer assembled protective surface coatings on wood. Applied surface science. 2017;396:1273-1281.

17. Khorasani SN, Ataei S, Neisiany RE. Microencapsulation of a coconut oil-based alkyd resin into poly (melamine-urea-formaldehyde) as shell for self-healing purposes. Progress in Organic Coatings. 2017;111:99106.

18. Stoye D, Freitag W. Types of paints \& coatings (Binders). Paints, Coatings and Solvents. 1998;11-100.

19. Andreas Giessmann. A practical guide to coating and laminating technologies: In coating substrates and textiles. 2012.

20. Buist JM, Grayson SJ, Woolley WD. Fire and cellular polymers. 1986.

21. Aaron Gene Robeils. Organic coatings: properties, selection, and use. 1968.

22. Tiarks F, Frechen T, Kirsch S, et al. Formulation effects on the distribution of pigment particles in paints. Progress in Organic Coatings. 2003;48(24):140-152. 